\section{The trumpet's blown pupil}

O

$\mathrm{n}$ the advice of a neurologist friend (author $\mathrm{CP}$ ), a 42-year-old man was rushed to hospital with a fixed dilated pupil (Figure, A). His condition was otherwise normal, as were the findings of urgent magnetic resonance imaging and angiography of the brain.

By Day 3, his mydriasis had resolved (as did the mystery) when the patient asked his "learned" friend how common eye injuries with whipper-snippers were. He mentioned, in passing, that on the morning of the incident he had cut back his beloved Angel's trumpet (Figure, B) - a member of the Solanaceae family, all parts of which are laced with anticholinergic alkaloids.

A detailed history, botanical or otherwise, will always trump the next best test.

Competing interests: No relevant disclosures.

Provenance: Not commissioned; not externally peer reviewed.

Chris Plummer FRACP, PhD

Adam Dangoor MRCP, $\mathrm{MD}^{2}$

ISt Vincent's Hospital, Melbourne, VIC.

2 Bristol Cancer Institute, Bristol, UK.

chris.plummer@svhm.org.au

doi: $10.5694 / \mathrm{mjal} 5.00150$ घ
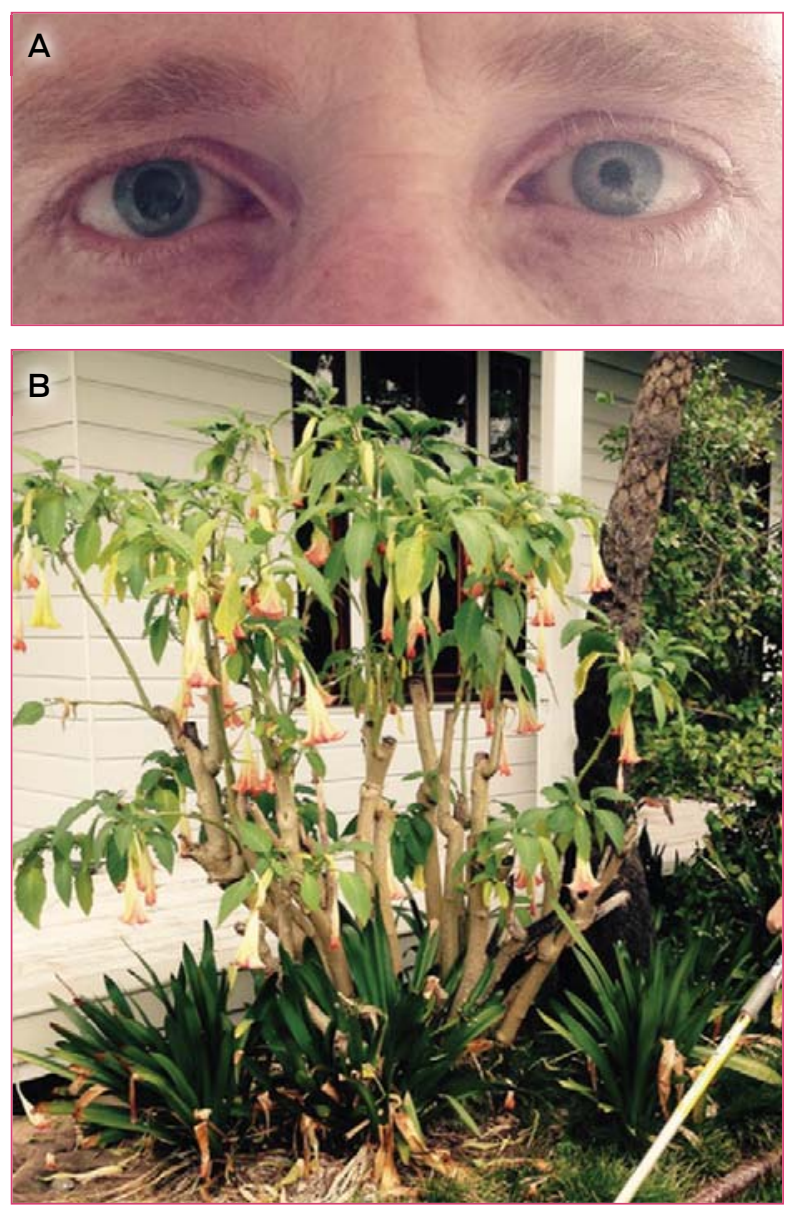